\title{
Formação para a vida democrática em John Dewey: alternativa contra a violência humana e política'
}

\section{Education for democratic life in John Dewey: alternative against human and political violence}

\section{Formación para la vida democrática en John Dewey: alternativa contra la violencia humana y política}

\author{
Claudio Almir Dalbosco ${ }^{2}$ \\ Universidade de Passo Fundo, Professor no Mestrado em Educação na Faculdade de \\ Educação
}

\begin{abstract}
Resumo: Neste ensaio considera-se a corrupção política como uma das principais formas de violência pública. Contrapõem a ela as reflexões feitas por John Dewey no capítulo VII de Democracia e educação. Partindo de sua noção de filosofia como crítica social, resume seu diagnóstico crítico sobre a nascente sociedade industrial, focando no espírito predador do industrial americano, baseado na economia liberal e no isolamento e exclusão social dele resultante. Reconstrói-se, na sequência, o ideal de formação democrática justificado pelo referido autor, destacando a importância de experiências comunitárias locais. Conclui-se defendendo a ideia de que oportunizar às novas gerações experiências formativas democráticas é o principal antídoto contra a corrupção como forma de violência política.
\end{abstract}

Palavras-chave: Educação. Democracia. Formação democrática. Cooperação social.

Abstract: This essay considers political corruption as one of the main forms of public violence. It contrasts it with the reflections by John Dewey in Chapter VII of Democracy and Education. Drawing on his notion of philosophy as social criticism, the essay summarizes his critical diagnosis of the nascent industrial society. It focuses on the predatory spirit of the American industrialist, which,

\footnotetext{
Agradeço ao CNPq, pela Bolsa Produtividade em Pesquisa, à UPF/RS, pelo financiamento das horas de pesquisa, e ao Núcleo de Pesquisa em Filosofia e Educação (NUPEFE), pelas discussões e inúmeras sugestões feitas a este texto.

2 Doutor em Filosofia pela Universität Kassel, Unikassel; Mestre em Filosofia pela Pontifícia Universidade Católica do Rio Grande do Sul.
} 
based on liberal economy, leads to the isolation and social exclusion. It then recreates the ideal of democratic education justified by the aforementioned author, highlighting the importance of local community experiences. It concludes by defending the idea that providing new generations with opportunities for democratic educational experiences is the main antidote to corruption as a form of political violence.

Keywords: Education. Democracy. Democratic education. Social cooperation.

Resumen: El ensayo considera la corrupción política como una de las principales formas de violencia pública. Contrapone a ella las reflexiones realizadas por John Dewey en el capítulo VII de Democracia y educación. Partiendo de su noción de filosofía como crítica social, resume su diagnóstico crítico sobre la naciente sociedad industrial, centrándose en el espíritu depredador del industrial americano, basado en la economía liberal y en el aislamiento y exclusión social que de él se deriva. En la secuencia, reconstruye el ideal de formación democrática justificado por el referido autor, destacando la importancia de experiencias comunitarias locales. Concluye defendiendo la idea de que dar experiencias formativas democráticas a las nuevas generaciones, es el principal antídoto contra la corrupción como forma de violencia política.

Palabras clave: Educación. Democracia. Formación democrática. Cooperación social.

\section{INTRODUÇÃO}

A crise atual agrava-se com o refinamento da corrupção do sistema político baseado na democracia representativa, a qual dá suporte, funcionando como pano de fundo, ao presidencialismo de coalização que rege o Brasil desde a Abertura Democrática. Não há dúvida de que a corrupção é a principal forma de violência política, que em decorrência do corporativismo e da irresponsabilidade dos próprios políticos, acentua a crise econômica e torna ainda mais aguda a injustiça social. O esgotamento do presidencialismo de coalização é visível, assim como o perfil das lideranças partidárias em evidência. 
Nesse contexto, imensas são as dificuldades para se encontrarem alternativas que possam ir além da reforma superficial do sistema político em vigor. O enfrentamento intelectual e político da crise profunda que assola o País, desdobrando-se na violência político-partidária explícita, implica aprofundar o debate acerca do modelo de nação almejado e, principalmente, sobre os ideais democráticos que precisam estar na base da formação republicana do espaço público. Pois o que está em questão na atualidade é a própria democracia como forma de vida e como organização social.

O diálogo cuidadoso com a tradição educacional democrática é uma contribuição que a filosofia da educação, preocupada com a formação humana e justiça social, pode dar ao debate sobre a situação social e a política atual. Considerando isso, pretendo fazer um pequeno experimento de pensamento tomando como referência a obra Democracia e Educação, publicada pelo pedagogo americano John Dewey, em 1916. O recurso a Dewey e, mais especificamente, ao capítulo VII da referida obra deve-se, entre outras razões, ao fato de se encontrar aí justificado de maneira original o nexo entre democracia e educação, abrindo espaço para pensar nossa própria crise político-educacional atual. Ao definir a democracia como forma de vida e ancorá-la na disposição humana participante, o pedagogo americano oferece argumentos potentes, desenvolvidos ainda no início do século passado, para pensar a inteligência coletiva como aspecto fundante da ação cooperativa.

Considerando que Dewey oferece uma justificação filosófica de sua noção de educação democrática, preciso iniciar com uma breve reconstrução de sua ideia de filosofia. Longe de se inserir na tradição da filosofia profissional, escolar e sistemática, ele a defende como forma de vida, isto é, como exercício meditativo da práxis humana e social. Na sequência, trato de seu diagnóstico de época, concentrando-me na sua crítica aos riscos inerentes à industrialização selvagem. Cabe destacar aqui o aspecto destrutivo que o procedimento industrial economicista provoca no trabalho humano, reduzindo a condição humana ao movimento corporal mecânico. Em seguida, refiro sua crítica ao isolamento social, interpretando-a como núcleo de sua posição contrária ao individualismo moderno. Por fim, trato de aspectos formativos do seu ideal democrático de 
educação, reservando espaço, nas conclusões finais, para pensar a possível atualidade do pensamento político-educacional de John Dewey.

\section{A IDEIA DE FILOSOFIA}

Considerando que Dewey dá ancoragem filosófica a suas noções de sociedade, educação e democracia, é importante iniciar com a problematização de sua própria ideia de filosofia. Ao longo da história da filosofia encontrase o projeto, sempre revigorado de uma maneira ou de outra, de tornar a filosofia ciência rigorosa. Na antiguidade grega, Aristóteles identificou, em sua Metafísica, a filosofia com a prothé ousia, colocando-a no ápice da pirâmide do conhecimento humano. Cabia a ela, como ontologia primeira, investigar os princípios últimos daquilo que é enquanto é. Portanto, com Aristóteles nasce a ideia de filosofia como ciência primeira, a qual, por ser a investigação dos primeiros princípios, possui acesso privilegiado à verdade, transformando-se em juíza suprema de toda a cultura humana.

Essa ideia de filosofia como ciência rigorosa revigora-se fortemente na modernidade, primeiro com René Descartes e, depois, com Immanuel Kant. Não aparece mais na forma de ontologia primeira que investiga os princípios últimos daquilo que é enquanto é, mas sim como teoria do conhecimento que possui a tarefa de investigar os fundamentos da realidade. Descartes funda, tanto no Discurso do Método quanto nas Meditações Metafísicas, a verdade do que existe na certeza do cogito, instaurando com isso a subjetividade como princípio fundante da modernidade. Kant assume tal princípio, oferecendo base transcendental para a estrutura do eu penso cartesiano. Para justificar o emprego teórico da razão pura e ao mesmo tempo deixar espaço aberto para o futuro emprego da razão pura prática, estabelece, na Crítica da Razão Pura, sua maior e principal obra, a distinção entre fenômeno e coisa em si. Enquanto atribui à teoria do conhecimento a investigação das condições de possibilidade da realidade como fenômeno, reserva à coisa em si incognoscível a outra dimensão da realidade que pode ser apenas pensada. 
Kant eleva a filosofia ao topo, tornando-se um dos principais responsáveis por sua profissionalização acadêmica, no âmbito da universidade alemã. Embora tenha feito a famosa distinção entre filosofia como conceito escolar (Schulbegriff) e filosofia como conceito de mundo (Weltbegriff), tendo consciência de que a filosofia deveria estar enraizada no mundo da vida dos seres humanos, concentra-se na árdua tarefa de pensá-la como sistema e, portanto, como conhecimento doutrinal. Com isso, atribui claramente à filosofia o papel de ser o tribunal da razão e, como dona da racionalidade, concede-lhe o poder conceitual de sustentar ou negar as pretensões da cultura como um todo. Nessa dimensão do projeto kantiano está presente a presunção arrogante do filósofo como profissional que possui condição privilegiada em relação às outras profissões. ${ }^{3}$

Nada mais estranho, para John Dewey, do que essa ideia de filosofia como dona da racionalidade e como juíza suprema da cultura. Mas sua crítica ao sentido doutrinal da filosofia não diminui sua condição de filósofo. Ao contrário, é justamente sua posição contrária à noção escolar de filosofia, fundada na teoria do conhecimento, que o torna um pensador atual, em condições de dialogar com outras áreas do saber humano e colocar a filosofia da educação no centro da relação entre democracia e educação. Ou seja, como deixarei claro logo a seguir, a relação entre teoria da educação e teoria da democracia é justificada por um tipo de filosofia da educação que já abriu mão de ser a primeira ciência e, por isso, não possui mais o papel de indicadora dos fundamentos para a educação e a pedagogia.

É paradigmático, nesse contexto, que Richard Rorty, em seu famoso livro A filosofia e o espelho da natureza, considera Dewey, juntamente com Martin Heidegger e Ludwig Wittgenstein, como um dos três filósofos mais importantes do século XX. Dewey abandona o sonho filosófico moderno do conhecimento como representação exata e, com isso, anula a epistemologia como disciplina possível. Essa postura assumida por ele abre-lhe outros

\footnotetext{
3 É bem verdade que a filosofia kantiana não pode ser reduzida à teoria do conhecimento. Em livro publicado ainda em 2002 procurei mostrar que no cerne de justificação da teoria do conhecimento, na Crítica da Razão Pura, Kant deixa espaço aberto (leerer Platz) para pensar outros empregos possíveis da razão, inclusive aqueles que vão além do emprego sistemático, tanto do ponto de vista moral quanto do estético (DALBOSCO, 2002).
} 
campos de investigação, destacando-se, entre os quais, os problemas estéticos e educacionais. Nas palavras de Rorty (1988, p. 22): “Dewey [...] redigiu a sua polêmica contra a tradicional imagética especular a partir da visão de um novo tipo de sociedade. Na sua sociedade ideal, a cultura não é mais dominada pelo ideal da cognição objetiva, mas pelo ideal de elevação estética."

Dewey está convencido, nesse contexto, de que a obsessão da filosofia moderna pela epistemologia a distanciou das formas de vida, cuja capacidade crítico-reflexiva ocorria de outra maneira, orientada pelas artes, educação e, principalmente, pela política. Ora, se a filosofia poderia ser levada adiante não mais apenas como "cognição objetiva", mas também e principalmente como reflexão crítica sobre outros temas que não são necessariamente epistemológicos, qual era então o problema que Dewey considerava como urgente em sua época? Embora tenha oferecido muitas formulações, o problema era de natureza moral e política. Segundo Bernstein (1986, p. 301): "A questão que Dewey considerava como mais central é a do caráter moral da própria 'vida comunitária'. E a democracia 'é a ideia mesma da vida comunitária'. " Bernstein oferece aqui, nesta passagem, uma importante indicação de que a noção de democracia de Dewey possui conteúdo eminentemente moral, ocupando-se com a problematização da vida comunitária.

Contudo, o vínculo profundo entre democracia e vida comunitária deixa-se esclarecer melhor - e esta é minha hipótese - com base na pressuposição antropológica que orienta a teoria da ação de Dewey e que também sustenta suas próprias convicções morais e pedagógicas. Tal pressuposição repousa na ideia de que o ser humano é um ser cooperativo porque alcança satisfação em suas atividades na medida em que elas preenchem fins e objetivos eminentemente comunitários. Ou seja, o ser humano pode desenvolver suas disposições e capacidades de maneira mais intensa e adequada quando se torna participante reconhecido da comunidade (HONNETH, 2000b, p. 136). Assegurar formas plurais de reconhecimento aos seus membros é um dever ético da comunidade humana. Mas como o reconhecimento que o ser humano almeja de seus pares não é dado, pois precisa ser conquistado, há, então, uma face nitidamente formativa (educacional) do vínculo entre democracia e vida comunitária. 
Cabe marcar, como resultado importante, que a crítica à obsessão moderna pela epistemologia e pelo ideal da cognição objetiva conduziu Dewey à ideia de filosofia como reflexão da dimensão moral da vida comunitária. Esse resultado permite-lhe pensar de maneira original tanto a teoria da democracia quanto a filosofia da educação. No que se refere à primeira, como interpreta Axel Honneth, Dewey não pode ser visto apenas como inspirador do republicanismo político, baseado na integração de todos os cidadãos em uma comunidade auto-organizada. Também, não é só o motivador intelectual da teoria procedimental da democracia, que atribui grande papel à orientação do procedimento racional para enfrentar problemas sociais e políticos. Muito além disso, Dewey é o fundador da noção ampliada de democracia baseada no modelo de cooperação social (HONNETH, 2000a, p. 285-286). Ora, é justamente essa noção de democracia que, segundo interpreto, concebe a educação como fonte principal de experiências formativas baseadas no espírito de cooperação solidária.

Essa noção mais ampla de filosofia permite Dewey ver a própria filosofia da educação como forma de tratar o vínculo entre moral e política, entre democracia e práxis humana. No contexto de sua grande obra Democracia e Educação, ele compreende a filosofia como sabedoria voltada para a reflexão da conduta humana (DEWEY, 2008, p. 332). Nesse sentido, a própria filosofia é uma forma de vida serena e resistente - e não simplesmente uma doutrina -, "frente às dificuldades e perdas, e até se supõe que é um poder para sofrer a dor sem se queixar." (DEWEY, 2008, p. 334). Ou seja, bem aos moldes do estoicismo antigo, compreende a filosofia como exercício reflexivo permanente de si sobre si mesmo visando ao fortalecimento moral do caráter contra os sofrimentos da vida. Contudo, de maneira bem mais acentuada do que os estoicos, reivindica o aspecto ativo e social da condição humana. ${ }^{4}$

Ora, é esse vínculo da filosofia com a condição humana ativa e com a práxis social que torna a educação um campo fértil de investigação. Com base

\footnotetext{
4 Richard J. Bernstein (1975) foi responsável pela reatualização da concepção filosófica e educacional de John Dewey, inserindo-a, nos anos setenta do século passado, no âmbito do debate das modernas teorias da ação. Da interpretação que ele faz do pensamento de Dewey assumo a noção de condição humana ativa.
} 
nesse vínculo, Dewey elege a filosofia da educação como maneira adequada de pensar o nexo entre democracia e educação. Como forma de vida baseada na postura serena e resistente, a filosofia auxilia então a educação a tomar consciência de si mesma. De outra parte, "o ponto de vista pedagógico nos capacita para considerar os problemas quando aparecem e lutam, quando se encontram em seu lugar e quando sua aceitação ou rechaço introduzem alguma diferença na prática." (DEWEY, 2008, p. 338). Em síntese, o diálogo entre filosofia e educação traz a própria filosofia para o terreno concreto da práxis social, impedindo que ela (a filosofia) se torne exclusivamente uma linguagem técnica restrita aos filósofos acadêmicos.

\section{DIAGNÓSTICO DE ÉPOCA: OS LIMITES HUMANOS DA INDUSTRIALIZAÇÃO SELUAGEM}

Dewey é um filósofo social que oferece diagnóstico crítico da sociedade de sua época, tomando tal diagnóstico como ponto de partida para pensar o vínculo entre democracia e educação e entre moral e política. Mais precisamente, a relação estreita entre democracia e educação depende, de acordo com sua perspectiva, da relação mais ampla entre educação e sociedade. Tal relação é uma constante ao longo da obra Democracia e Educação, mostrando-se especialmente no capítulo VII, no qual a noção de sociedade é justificada por via negativa. Ou seja, Dewey nega primeiro o princípio da lucratividade a qualquer preço da nascente sociedade industrial, porque ele vê em tal princípio a forma violenta de destruição das relações humanas, para esboçar, em seguida, os ideais da sociedade democrática, baseada no trabalho humano como processo autoformativo.

Não podemos esquecer, nesse sentido, que Democracia e Educação é uma obra de 1916 e, portanto, diz respeito ao início mais intenso da industrialização americana. Dewey manifesta preocupações pontuais sobre a sociedade industrial que devem ser consideradas para tratar da relação entre educação e sociedade e, especificamente, entre democracia e educação. Tais 
preocupações auxiliam para desfazer a crítica equivocada dirigida contra seu pensamento, que o acusa de ser um adepto fervoroso do desenvolvimento industrial americano. Como deixarei claro logo a seguir, ele considera o desenvolvimento industrial importante, mas desde que esteja a serviço da cooperação social e do desenvolvimento humano.

problema de fundo que o leva a criticar a sociedade industrial se refere ao modo como a divisão social do trabalho nela existente impende o desenvolvimento autônomo de seus membros. Nesse caso, a sociedade industrial reproduz, em outro contexto social e político, o mesmo tipo de subserviência próprio à sociedade aristocrática. Trabalhar no interior da fábrica, fazendo sempre os mesmos movimentos e com o olhar dirigido somente à máquina não difere muito do servo que vive na gleba, sob o mando autoritário do senhor, sem direito à educação e à própria vida espiritual mais ampla. É nesse contexto que se pode compreender a crítica que o pedagogo americano faz à organização científica do trabalho que estava em voga na época. Tal organização - e aí Dewey tem certamente em vista o modelo fordista de organização do trabalho que estava ainda em seu início - pensava somente na eficiência das disposições corporais do trabalhador, na agilidade de seus músculos, visando com isso tirar o máximo de lucro de seu trabalho. Pensava-se na melhor forma de organização do trabalho humano para extrair o maior lucro possível. Nesse sentido, quanto mais ágil na repetição de seus movimentos, mais rendimento produtivo o trabalhador daria ao seu trabalho.

Dewey é contra, portanto, o capitalismo economicista desumanizador, o qual, ao focar exclusivamente na lucratividade, ignora o trabalhador em sua globalidade, deixando de tratá-lo como ser de cultura, com vida espiritual própria. Reduzido a tal condição, de mero operador mecânico, o trabalhador torna-se um escravo moderno, tendo de vender sua própria alma ao capitalista industrial. Consagra-se a uma atividade que é útil socialmente, mas sem compreender a própria utilidade. Torna-se um autômato que executa tarefas, sem a disposição intelectual de poder compreendê-las. Com essa linha de crítica à industrialização americana e ao espírito mercantilista do industrial 
americano, exposta em Democracia e Educação, Dewey está muito mais próximo da tradição da teoria crítica do que ela própria imagina. ${ }^{5}$

Reduzida à investigação das operações corporais (musculares) do trabalhador, a ciência deixa de se dedicar ao descobrimento das relações do ser humano com seu trabalho, incluindo as relações com os demais trabalhadores, que participam do mesmo processo produtivo. Ou seja, o reducionismo científico da época ignora a dimensão social e formativa inerente ao trabalho humano e, com isso, não investiga o quanto o próprio trabalho poderia ser uma fonte de desenvolvimento das capacidades intelectuais humanas. De outra parte, os industriais estavam conscientes de que se o trabalho humano assumisse essa dimensão formativa, terminaria por interferir nos resultados econômicos finais da atividade produtiva.

Nesse contexto, indo além das relações meramente mecânicas, o trabalhador poderia ver as dimensões sociais e intelectuais de seu próprio trabalho. Dewey (2008, p. 92) critica pontualmente o pensamento industrial tacanho: "A inteligência se reduz aos fatores que concernem à produção técnica e à comercialização de mercadorias." Pensar na dimensão formativa do trabalho implica vê-lo também como produção social e cultural, na qual o trabalhador, colocando nela sua vida, pode se realizar como pessoa. Ou seja, se o desenvolvimento industrial é a mola da nova sociedade, as relações de trabalho que ocorriam dentro da fábrica deveriam ativar as disposições intelectuais do trabalhador. Somente assim a organização industrial poderia contribuir para a formação da sociedade democrática. É nesse sentido que Dewey, inserindo-se bem no âmbito da tradição do pensamento crítico, insiste no aspecto formativo do trabalho humano: deve ser um fator de desenvolvimento da inteligência humana e não a causa do embrutecimento físico e intelectual do trabalhador.

$\bigcirc$ que está em questão nessa crítica de Dewey ao desenvolvimento industrial economicista? É o ideal de autodeterminação que a sociedade, independentemente de sua forma, deve proporcionar aos seus membros,

\footnotetext{
5 Sobre o problema da relação entre pragmatismo e teoria crítica ver o trabalho Pragmatismus und Gesellschaftstheorie (Pragmatismo e teoria crítica) de Hans Joas (1992). Nesse estudo Joas desfaz criticamente muitos estereótipos elaborados pela primeira geração de pensadores da teoria crítica, como Adorno e Horkheimer, contra o pragmatismo americano.
} 
contando com o auxílio inestimável da educação. $\bigcirc$ pensamento industrial restrito, que visa somente ao lucro, não considera o trabalhador como ser humano que possui muitos outros interesses que vão além da satisfação de suas necessidades imediatas, que possui muitas outras disposições, além da capacidade de manusear mecanicamente os instrumentos que estão à sua frente. Em síntese, o que está em jogo, portanto, nessa contraposição deweyana aos industriais com mentalidade reduzida, é o ideal de educação como desenvolvimento integral do ser humano, em todas as suas direções. A educação pelo trabalho que se limita simplesmente em aperfeiçoar o movimento muscular do trabalhador ignora a possibilidade de tal desenvolvimento. Nesse sentido Dewey insere-se na tradição neohumanista do século XIX, a qual, nas figuras tanto de Wilhelm von Humboldt quanto de Johann F. Herbart, previa o desenvolvimento das capacidades humanas em diversas direções.

Daí a importância, do ponto de vista educacional, de investigar a inteligência do trabalhador formada nas relações sociais que ele mantém na esfera de seu trabalho e as possibilidades formativas de ampliá-la para além do que é feito no interior da fábrica. Além das operações mecânicas proporcionadas pelos músculos, também se faz necessário considerar o trabalhador como um ser emocional, que possui sentimentos e uma vida social ativa, com interesses e aspirações que não se reduzem ao mundo da fábrica. Além da mecânica corporal, faz-se necessário tomá-lo como ser espiritual, com capacidades intelectuais aptas a serem desenvolvidas em diferentes direções. Em síntese, Dewey estava consciente de que a sociedade democrática dependia muito da dimensão formativa do trabalho humano. Por isso, justifica-se sua crítica ao liberalismo econômico subjacente à visão de mundo do industrial americano de sua época.

\section{CRÍTICA AO ISOLAMENTO SOCIAL}

Na seção anterior tratei dos limites formativos da sociedade industrial, considerando, como núcleo da crítica de John Dewey, que tal sociedade limita o desenvolvimento das capacidades intelectuais do trabalhador. Isso 
corre, sobretudo, quando tal sociedade foca somente no exercício corporal do trabalhador, objetivando, com isso, maior eficiência de seus resultados produtivos e maior lucratividade econômica. $\bigcirc$ mesmo processo limitante de formação das capacidades do trabalhador pode ser verificado na formação profissional do educando, sobretudo daquela formação voltada para o trabalho industrial. A ausência da formação espiritual ampla do trabalhador compromete a cooperação social e, com isso, a própria democracia como forma de vida.

Se o trabalho humano possui uma dimensão social e mesmo assim pode não se tornar formativo, a situação do isolamento social é ainda mais precária. $\bigcirc$ educando isolado não se forma, mas se deforma. É da condição humana e da própria condição dos grupos sociais a dinâmica do intercâmbio entre si. As capacidades intelectuais humanas e a sociedade como um todo se desenvolvem quando promovem intensa interação recíproca. $\bigcirc$ vai e vem do relacionamento humano, assegurado principalmente pela ação comunicativa entre os seres humanos, é condição de possibilidade para o crescimento individual e social. ${ }^{6}$ Em circunstâncias nas quais não há interação mediada simbolicamente, ou seja, não há ação comunicativa, o potencial humano e social estagna, embrutecendo o ser humano. $\bigcirc$ caso prototípico dessas circunstâncias é o isolamento individual ou do grupo social.

Considerando isso, Dewey dedica alguns parágrafos do capítulo VII de Democracia e Educação para tratar do problema do isolamento. $\bigcirc$ que esse fenômeno causa primeiramente é o espírito antissocial, acentuando a competitividade destrutiva entre os membros da sociedade. O espírito antissocial é a antípoda da vida comunitária local e, com isso, o principal impedimento da democracia como forma de vida. Dewey trata aqui de um tipo específico de isolamento, o qual não pode ser confundido com a solidão necessária que é buscada pelo ser humano, compreendida como sua retirada consciente do meio social para poder pensar sobre si mesmo e sua inserção no grupo social. Nesse sentido, solidão não é a mesma coisa que isolamento: enquanto esse

\footnotetext{
6 É notório, nesse sentido, o quanto as ideias filosóficas e educacionais de Dewey são tributárias da teoria da ação desenvolvida por Georg Herbert Mead em suas preleções proferidas durante décadas na Universidade de Chicago e publicada, posteriormente, como livro (MEAD, 1992). Para a análise dessa influência ver Hans Joas (2000).
} 
último corta o vínculo do ser humano com outros seres humanos, negando os sentimentos morais mais profundos, como a interdependência, a justiça e a solidariedade, a solidão é uma forma de, retirando-se momentaneamente da participação na vida pública, pensá-los (tais sentimentos) no espaço da interioridade humana. Nesse sentido, solidão é a decisão intelectual pessoal de estar a sós consigo mesmo para poder pensar em silêncio e com profundidade o significado do viver junto, na companhia um com o outro. É justamente nessa perspectiva que Humboldt, o grande idealizador da modernização universitária alemã, coloca, no século XIX, a solidão, juntamente com a liberdade, como pilar da universidade. Compreende-a como impulso da atividade espiritual mais profunda, pois sem o diálogo consigo mesmo não há como refletir sobre as coisas em geral e os assuntos humanos em especial.

Ao contrário disso, o isolamento é a característica básica do espírito antissocial porque potencializa os interesses egoístas do ser humano e de seu grupo social. Estimula e fortalece o espírito corporativo que só foca no interesse individual imediato, sem se preocupar com os interesses comuns de outros seres humanos e grupos sociais. $\bigcirc$ espírito corporativo é o principal entrave da cooperação social. Por isso, não é difícil de compreender a insistência crítica de Dewey ao isolamento, porque tem consciência de que o mesmo, enquanto laço social destrutivo, inviabiliza o espírito de cooperação social indispensável à constituição da democracia como forma de vida e organização social. $\bigcirc$ efeito danoso do isolamento não tem alcance somente individual. Não permanece somente na esfera do ser humano individual, uma vez que bloqueia a interação comunicativa entre os próprios grupos sociais. $\bigcirc$ espírito individualista, que toma conta do comportamento do ser humano que vive na sociedade urbanoindustrial, espalha-se para o grupo todo. Agindo de maneira interesseira e agressiva em relação aos outros grupos, o grupo social termina por se autoisolar em relação a tais grupos. A atitude contrária dos outros grupos é naturalmente de autoproteção, pois a aceitação passiva da agressividade individualista de qualquer grupo leva à destruição da cooperação social.

Ao tratar desse tema, Dewey está chamando a atenção para um fenômeno individual e social de primeira grandeza: o isolamento individualista e de grupo é o principal predador da tessitura social orgânica que visa à formação 
do espírito de cooperação solidária. Destrutivo da ordem social solidária, o isolamento individualista precisa ser enfrentado educacionalmente. A tarefa da educação consiste em desenvolver experiências concretas que oportunizem ao educador e ao educando a formação do espírito de cooperação social. Nesse sentido, compete aos grupos sociais família e escola, como as duas primeiras formas de socialização do ser humano, trabalharem na formação do espírito de cooperação. Dar um conteúdo formativo ao grupo significa direcioná-lo para a solidariedade. Se a criança for inserida em ambientes familiares e escolares, nos quais há boas experiências de solidariedade, ela encontra referência sólida para fazer internamente o contraponto da sua própria propensão humana ao isolamento individualista. Não há outra forma senão as experiências coletivas concretas de vivência mútua para fazer frente à tendência humana ao isolamento, preocupado em cuidar somente de seus interesses individuais.

Mas por que Dewey insiste tanto na valorização de experiências educacionais concretas, voltadas para a formação do espírito de cooperação social? Porque acredita que a forma de vida democrática no espaço público mais amplo depende do processo formativo que precisa iniciar já na infância. Às crianças precisam ser oportunizadas experiências formativas concretas que as exercitem no espírito de cooperação solidária. Da crítica ao isolamento individualista, baseada em experiências concretas de formação, resulta o educando disposto a intervir no espaço público orientado por ideias de cooperação e solidariedade.

\section{ASPECTOS FORMATIUOS DO IDEAL DEMOCRÁTICO}

É com a educação para a vida democrática que, segundo Dewey, pode-se romper com o isolamento social e o espírito individualista que o acompanha. Compreender o que Dewey entende por democracia e o seu vínculo com a educação não é tarefa fácil. Vou me limitar aqui, conforme já anunciado anteriormente, ao capítulo VII de Democracia e Educação, no qual o referido autor desenvolve o ideal democrático que embasa sua compreensão 
de democracia como forma de vida. Cabe insistir mais uma vez, conforme exposto anteriormente, que sua ideia de democracia como forma de vida só faz sentido quando associada a sua própria concepção de filosofia como forma de vida, cuja tarefa principal é pensar serenamente as intempéries da vida, visando ao fortalecimento moral da condição humana. Como o individualismo humano que resulta do isolamento social é o principal obstáculo à condição social da vida humana, os processos formativos são a melhor maneira de enfrentá-lo. É pela educação que se forma o espírito de cooperação social indispensável para superar a inclinação humana ao individualismo.

Mas qual é exatamente o ideal democrático desenvolvido aí por Dewey? Tal ideal assume dupla dimensão: diz respeito, primeiramente, aos interesses que são construídos de maneira comum e reconhecidos como fator de governo ou direção social; refere-se, em segundo lugar, à interação mais livre entre os grupos sociais, acompanhada pela mudança nos hábitos sociais. Dewey esclarece, ainda nessa segunda dimensão do ideal democrático, que a atualização permanente dos hábitos sociais possibilita enfrentar as novas situações que são produzidas pelo relacionamento social variado. Em síntese, interesses comuns orientados pela participação de todos e liberdade de ação são duas dimensões do ideal democrático defendido pelo pedagogo americano.

A importância educativa dessa dupla dimensão torna-se saliente. Os interesses sociais que se interpenetram, ou seja, a interação social recíproca exige processos educativos no sentido moral, uma vez que se os agentes sociais não aprenderem a se colocar no lugar do outro, permanecem no âmbito do isolamento social. Colocar-se no lugar do outro exige longo processo formativo e, por isso, o vínculo estreito entre democracia e educação. No dizer do próprio Dewey, "a comunidade democrática [é] mais interessada do que outras em organizar uma educação deliberada e sistemática. (DEWEY, 2008, p. 93). Considera, então, que a "devoção da democracia à educação é um fato familiar." (DEWEY, 2008, p. 93).

Esse nexo estreito entre democracia e educação precisa ser melhor esclarecido. Faz-se necessário então tomar mais de perto o significado da expressão "interesses sociais comuns", pois tal expressão constitui, conforme afirmei anteriormente, a primeira dimensão ou o primeiro pilar da democracia. 
Há algo de decisivo em relação a tais interesses: não podem ser impostos de fora, mas, sim, construídos participativamente. Ora, tanto a postura adotada para tal construção quanto o conteúdo que dela brota, para que possam ser participativos, precisam ser formados. Em síntese, se os interesses sociais só se tornam comuns pela participação, esta, por sua vez, necessita de formação. Então, formação participativa é o núcleo da educação democrática, simplesmente porque está na base da cooperação social.

É precisamente isso o que o pensamento de Dewey exige quando torna familiar a devoção da democracia à educação. Tem plena consciência de que o espírito participativo exigido para a definição dos interesses comuns depende do processo educativo capaz de criar experiências formativas de cooperação solidária. Caso contrário, os interesses sociais comuns são impostos e, deixando de ser recíprocos, tornam-se autoritários. Portanto, sem educação no sentido formativo não há democracia. A participação ou a disposição humana participante define aqui o próprio sentido de formação. De outra parte, é preciso considerar que nem toda a educação é formativa e nem toda a formação é participante. Tanto educação quanto formação são fenômenos sociais profundamente ambíguos. Os processos educativos autoritários não conduzem obviamente para o espírito participante. Não ativam a capacidade humana participante. A própria formação, nesse sentido, não possui um vínculo essencial e inquestionável com a participação. Às vezes, mesmo querendo educar, deseduca, transformando-se rapidamente em deformação. Em contextos educacionais autoritários, a formação humana deforma-se porque não oportuniza a disposição participante.

Inúmeros exemplos que acontecem em diferentes situações pedagógicas específicas ajudam na elucidação desse problema. No contexto familiar, a educação assume o modo de disposição participante quando os pais dialogam minimamente com seus filhos para planejar as tarefas cotidianas. Contudo, a agenda dos afazeres cotidianos pode ser simplesmente imposta aos filhos pelos pais, sem que os primeiros tenham a oportunidade de manifestar sua vontade. Quando a educação assume o modo dialógico, torna-se formativa; do contrário, gera o espírito passivo e de subserviência dos próprios filhos. $\bigcirc$ mesmo vale para o contexto de sala de aula, quando o professor impõe o 
conteúdo e método de ensino aos alunos, simplesmente desconsiderando suas experiências formativas próprias. Não ativando sua disposição participante, mantém os alunos na condição passiva.

Preciso referir agora o passo adiante dado por Dewey, ainda no interior do capítulo VII de Democracia e Educação, uma vez que tal passo é importante para meus propósitos. Apoiando-se na capacidade humana participante, a sociedade democrática repudia o princípio da autoridade externa. Assim, é a própria comunidade dos seres humanos, no sentido mais amplo, e a comunidade do grupo local, no sentido mais restrito, que formam o espaço público no qual ocorre a tomada de decisões. Importante é, nesse contexto, para o pensador americano, que os interesses comuns estabelecidos pela ampla comunidade humana dependem de experiências formativas concretas, pois é exatamente aí que começam a se desenvolver as principais características democráticas da capacidade participante que dão solidez ao espaço público ampliado. Experiências concretas da comunidade local constituem a base indispensável da cooperação social mais ampla.

Isso significa dizer, do ponto de vista especificamente pedagógico, que quanto mais oportunidades as crianças tiverem em seus grupos sociais imediatos, como a família e a escola, para ativarem sua disposição participante, mais formam seu espírito de cooperação social. Isso soa trivial, mas pode passar desapercebido pelas gerações mais velhas, quando se relacionam formativamente com as gerações mais novas. Esse esquecimento da capacidade participante como constitutiva da condição humana e a importância de sua formação para a definição democrática do espaço público mais amplo acentuase em contextos sociais e políticos fechados e autoritários. Ou seja, quanto mais autoritárias forem as instituições, incluindo entre elas a família e a escola, mais ignoram a capacidade participante como constitutiva da condição humana. Daí a importância, para Dewey, da valorização pedagógica das experiências comunitárias locais como forma eficiente de fortalecimento da cooperação social mais ampla.

Gostaria de acentuar novamente o que foi afirmado anteriormente como núcleo do nexo entre democracia e educação, a saber, que a própria democracia exige a recusa explícita do princípio da autoridade externa. Isso 
gera muitas consequências para o modo de pensar e viver do ser humano contemporâneo. Tal recusa exige dele tomar as rédeas de seu próprio destino, ao mesmo tempo em que permite valorizar os pequenos acontecimentos e as experiências locais como constitutivas da sociedade mais ampla. A recusa da autoridade externa, ao mesmo tempo em que concede maior liberdade de ação ao ser humano, exige-lhe mais responsabilidade. Formar a liberdade responsável é, então, a grande tarefa da educação e, desse modo, a formação da capacidade participante baseada na liberdade responsável é o núcleo do nexo entre democracia e educação.

Se o olhar voltado aos céus ou ao poder do soberano não serve mais para dar sentido à ação humana no espaço político contemporâneo, então é preciso encontrar o substituto na disposição e no próprio interesse humano. A capacidade humana participante representa, sob esse aspecto, a secularização do princípio da autoridade externa. Contudo, para além desse aspecto teológico-político, há, segundo Dewey (2008, p. 82), um sentido mais profundo: "A democracia é mais que uma forma de governo; é primeiramente um modo de viver associado, de experiência comunicada conjuntamente." Há, desse modo, nessa breve passagem, dois traços distintivos e indispensáveis da noção de democracia de John Dewey: um modo de viver associado e uma experiência comunicada (construída) coletivamente. Isso significa, então, que sem uma forma associada de vida, construída coletivamente, não há democracia. Contudo, sendo um modo associado de vida, a democracia precisa ser formada, pois se for imposta, fere o princípio da condição humana mais elementar e decisiva, a saber, sua capacidade participante.

\section{CONSIDERAÇÕES CONCLUSIUAS: POSSÍUEL ATUALIDADE DO PENSAMENTO DE JOHN DEWEY}

Procurei mostrar nas reflexões desenvolvidas que Dewey defende filosoficamente o nexo entre democracia e educação. Para fazê-lo, distancia-se da noção escolar moderna de filosofia, compreendida como epistemologia que 
investiga as condições da verdade objetiva. Com forte inspiração estoica e por influência da teoria pragmatista da ação, compreende a filosofia como forma de vida que possui a tarefa de refletir sobre a dimensão social e comunitária da práxis humana. Para assumir essa condição reflexiva, a filosofia precisa problematizar a condição humana, concentrando-se em sua capacidade participante.

De outra parte, como filósofo social, Dewey compreende a educação como fenômeno social e, justamente por causa disso, tem consciência de que o aprofundamento do nexo entre democracia e educação depende da investigação sobre a condição humana inserida na ordem social. Impulsionado por esse motivo, critica o modo como a nascente industrialização capitalista, alavancada pela economia liberal e pela ciência industrial correspondente, reduz o trabalho humano no interior da fábrica ao aperfeiçoamento mecânico dos movimentos corporais (musculares). A redução da condição humana a uma máquina que opera eficientemente ignora aquilo que é propriamente indispensável para a formação da democracia como forma de vida e organização social, a saber, o desenvolvimento das disposições espirituais impulsionado pela capacidade participante.

A redução da condição humana ao aperfeiçoamento dos movimentos corporais mecânicos tem sua correspondência política no isolamento social, como forma específica de manifestação do individualismo moderno. Ou seja, reduzido à máquina na fábrica e isolado socialmente, o ser humano não possui as mínimas condições materiais e espirituais de levar uma vida digna, sendo podado em sua capacidade de cooperar solidariamente. Para fazer frente a esse problema, Dewey pensa a educação democrática, alicerçando-a na capacidade participante da condição humana. Tomando tal capacidade como núcleo da sociabilidade humana, desenvolve experiências formativas concretas, escolares e extraescolares, intentando, com isso, incentivar nos educandos o espírito de cooperação social. A experiência da escola- laboratório desenvolvida na Universidade de Chicago surge justamente nesse contexto, para oportunizar às crianças experiências formativas concretas de cooperação 
e solidariedade, sendo isso decisivo para sua futura participação democrática no espaço público ampliado. ${ }^{7}$

Muitos aspectos da educação democrática pensada por Dewey estão desatualizados. $\bigcirc$ modelo industrial fordista foi suplantado pela aliança estreita entre capital financeiro, tecnologia digital e sociedade de consumo. Mas a desumanização do trabalho humano só tendeu a aumentar, quer na forma de crescimento vertiginoso da ausência de trabalho, ou seja, do próprio desemprego, quer nas novas configurações que o trabalho humano assume na sociedade digital terceirizada. Nesse sentido, torna-se oportuno perguntar se a sociedade digital vigente não está impondo, por outras vias, o mesmo processo de embrutecimento do ser humano provocado pela nascente sociedade industrial americana da época. Ou seja, a tecnologia digital não seria uma nova forma de servidão, na medida em que mantém a multidão prisioneira de si mesma?

Em síntese, para ver a atualidade do pensamento de Dewey sobre os efeitos destrutivos que a industrialização tacanha provoca na formação humana teríamos que investigar a semelhança entre a atividade muscular mecânica do trabalhador, ao executar sempre a mesma atividade, e o olhar fixo e imóvel do ser humano atual no dispositivo digital, seguindo repetidamente o movimento de seus dedos ou a tonalidade de sua voz para editar a mensagem. A incapacidade de pensamento manifesta outrora, no interior da fábrica, não estaria se repetindo agora, no gesto do andante solitário que caminha na rua e, obcecado pelo seu aparelho digital, não vê o que está acontecendo a sua volta?

Do ponto de vista da crítica social, o espírito corporativista acentuado do industrial moderno, denunciado com todas as letras por Dewey em 1916, parece ter migrado, no cenário econômico e político do Brasil atual, para a aliança incestuosa entre os partidos políticos e os grandes grupos econômicos. Alimentados pela voracidade lucrativa e pelo ganho fácil e desonesto, políticos e empresários surrupiam o dinheiro público sem se importarem minimamente com as consequências éticas e sociais de sua ação. A privatização ilícita do bem público, levada adiante pela engenhosa corrupção econômico-política,

\footnotetext{
7 Para uma exposição detalhada da escola-laboratório criada por Dewey na Universidade de Chicago, ver a primeira parte do livro de Oelkers (2009).
} 
acentua a injustiça social, empurrando com ela parte significativa da população brasileira de volta para a mais absoluta pobreza. Esse é o caso típico de violência pública, no qual o espírito corporativo individualista destrói as possibilidades de justiça social.

Desse modo, diante do aumento desordenado do espírito corporativo contemporâneo, que alimenta a corrupção social e política, acentuando também a desresponsabilização de políticos e empresários pela coisa pública, faz-se ainda mais urgente o sentido da educação democrática. No momento em que o espaço público está profundamente danificado, em parte também pelos próprios limites do sistema político em vigor, torna-se indispensável avançar em novas formas de organização política que possam contrabalançar com o modelo exclusivista e profundamente excludente da democracia representativa. Pois como a situação brasileira atual mostra de maneira exemplar, o exercício do poder tripartite entre executivo, legislativo e judiciário, quando deixando a si mesmo, desenraiza-se notoriamente de demandas sociais e culturais existentes.

Investir esforços pedagógicos em experiências formativas localizadas, que fomentem o espírito de cooperação social responsável, é um grande desafio da educação atual. Nesse sentido, quanto família como escola, enquanto exemplos paradigmáticos da "comunidade local", continuam desempenhando papel educacional importante. Nesses espaços, as crianças podem aprender pelo exercício de sua própria experiência que a existência social cooperativa depende do grupo e que sua humanidade é alcançada quando forem capazes de levar a sério em suas ações o ponto de vista, o modo de ação e as reivindicações dos outros. Ora, é justamente no contexto brasileiro atual, marcado pela corrupção econômica e política, que formar para a cooperação social solidária continua sendo tarefa central da educação democrática.

\section{REFERÊNCIAS}

BERNSTEIN, R. J. Praxis und Handeln. Frankfurt am Main: Suhrkamp, 1975.

BERNSTEIN, R. J. Perfiles Filosóficos. Tradução Martí Mur Ubasart. Madrid: Espanha, 1991. 
DALBOSCO, C. A. Ding an sich und Erscheinung. Perspektiven des transzendentalen Idealismus bei Kant. Wüzburg: Königshausen \& Neumann, 2002.

DEWEY, J. The Middle Works, 1899-1924: Volume 9: Democracy and Education. Illinois: Southern Illinois University Press, 2008.

HONNETH, A. Das Andere der Gerechtigkeit. Afsätze zur praktischen Philosophie. Frankfurt am Main: Suhrkamp, 2000.

HONNETH, A. Zwischen Prozeduralismus und Teleologie. Ein ungelöster Konflikt in der Moraltheorie von John Dewey. In: JOAS, Hans (Hrgs). Philosophie der Demokratie. Beiträge zum Werk von John Dewey. Frankfurt am Main: Suhrkamp, 2000, p. 116-138.

JOAS, H. Pragmatismus und Gesellschaftstehorie. Frankfurt am Main: Suhrkamp, 1992.

JOAS, H. Praktische Intersubjektivität. Die Entwicklung des Werkes von G. H. Mead. Frankfurt am Main: Suhrkamp, 2000.

MEAD, G. H. Mind, Self and Society. From the standpoint of a social behaviorist. Chicago: University of Chicago Press, 1992.

OELKERS, J. John Dewey und die Pädagogik. Weinheim und Basel: Belz Verlag, 2009.

RORTY, R. A filosofia e o espelho da natureza. Tradução de Jorge Pires. Lisboa: Publicações Dom Quixote, 1998.

Recebido em: 23 de outubro de 2017 Aceito em: 14 de março de 2018

Endereço para correspondência: Avenida Brasil Leste, 285, São José, 99052900, Passo Fundo, Rio Grande do Sul, Brasil; vcdalbosco@hotmail.com 